\title{
Los fármacos como materia patentable y el encuadre del COVID-19 en la licencia del artículo 45 de la Ley 24481
}

\author{
$* * * *$ \\ Martín Ugalde \\ Universidad Nacional de Mar del Plata \\ tinchougalde@gmail.com
}

Recibido: 2 de noviembre de 2020

Aceptado: 26 de noviembre de 2020

\section{Resumen}

A principios del año 2020, la Organización Mundial de la Salud declaró al COVID-19 como una pandemia. No hace falta hacer un análisis exhaustivo para advertir las importantes consecuencias sanitarias, económicas y jurídicas que aquella ha tenido.

En particular, el derecho de patentes tiene un importante rol en este sentido. La posibilidad de que se patente una vacuna en el país con el ordenamiento vigente de la Ley 24481 y sus modificatorias y que se proteja el derecho humano de propiedad que el titular tiene sobre ella tiene un fuerte impacto en el incentivo al desarrollo técnico y científico. Derecho que no puede analizarse en forma aislada, sino en el contexto de emergencia sanitaria que hoy está imperando a nivel mundial y el interés público en la protección de otro derecho humano, como es la salud pública. Este desarrollo técnico incentivado por el sistema de patentes forma parte del interés no solo de la comunidad jurídica, sino de la sociedad toda. En este trabajo, analizaremos el contexto de la pandemia y el derecho de la propiedad intelectual, la evolución histórica en la legislación argentina en la posibilidad de patentar productos y procedimientos farmacológicos, los requisitos que debe cumplir la vacuna para ser considerada materia patentable en los términos de la ley, el procedimiento que hay que seguir ante el INPI para su patentamiento, los derechos que la ley otorga al titular de la patente de la vacuna y su encuadre la licencia obligatoria en contexto de emergencia sanitaria del artículo 45 de la Ley de Patentes.

Palabras clave: COVID-19, patentes de fármacos, licencia obligatoria, derecho a la salud. 


\title{
Drugs as Patentable Subject and the Setting of COVID-19 in the License of Article 45 of Law 24481
}

\begin{abstract}
At the beginning of 2020, the World Health Organization declared COVID-19 a Pandemic. It is not necessary to do an exhaustive analysis to notice the important health, economic and legal consequences that it has had.

In particular, Patent Law plays an important role in this regard, the possibility of a vaccine being patented in the country with the current ordinance of Law No. 24,481 and its amendments, and that the human right of property that the holder has on it, has a strong impact on the incentive to technical and scientific development. A right that cannot be analyzed in isolation, but in the context of the health emergency that is prevailing worldwide today and the public interest in the protection of another human right such as public health.

The aforementioned technical development encouraged by the patent system is part of the interest not only of the legal community, but of society as a whole. In this paper we will analyze the context of the pandemic and Intellectual Property Law, the historical evolution in Argentine legislation regarding the possibility of patenting pharmacological products and procedures, the requirements that the vaccine must meet to be considered patentable matter in terms of the law, the procedure to be followed before the INPI for its patenting, the rights that the law grants to the owner of the vaccine patent and its framing in the Compulsory License in the context of a health emergency of Art. 45 of the Patent Law.
\end{abstract}

Key words: COVID-19, drugs patents, compulsory license, right to health.

\section{Medicamentos como matéria patenteável e enquadramento da COVID-19 na licença do artigo 45 da Lei 24481}

\section{Resumo}

No início de 2020, a Organização Mundial da Saúde declarou a COVID-19 uma pandemia. Não é necessário fazer uma análise exaustiva para perceber as importantes consequências para a saúde, econômicas e jurídicas que isso teve.

Em particular, a Lei de Patentes desempenha um papel importante nesse quesito, pela possibilidade de uma vacina ser patenteada no país com o atual decreto da Lei no 24481 e suas alteraçóes, e que o direito humano de propriedade que o titular tem sobre ele, tem forte impacto no incentivo ao desenvolvimento técnico e científico. Um direito que não pode ser analisado isoladamente, mas no contexto da emergência sanitária que hoje prevalece em todo o mundo e do interesse público em proteger outro direito humano como a saúde pública.

O referido desenvolvimento técnico incentivado pelo sistema de patentes faz parte do interesse náo só da comunidade jurídica, mas da sociedade como um todo. Neste artigo analisaremos o contexto da pandemia e do Direito de Propriedade Intelectual, a evolução histórica da legislação argentina quanto à possibilidade de patentear produtos e procedimentos farmacológicos, os requisitos que a vacina deve cumprir para ser considerada matéria patenteável em termos de a lei, 
o procedimento a ser seguido perante o INPI para o seu patenteamento, os direitos que a lei confere ao titular da patente de vacina e seu enquadramento na Licença Compulsória no âmbito de uma emergência sanitária do Art. 45 a Lei de Patentes.

Palavras chave: COVID-19, patente de medicamento, licença compulsória, direito à saúde.

\section{Introducción: implicancias del contexto}

Antes de proceder a desarrollar el tema principal, es pertinente dedicar algunos párrafos a enunciar el contexto en el que este trabajo ha sido escrito, los efectos sanitarios, económicos y jurídicos que aquel ha tenido y su impacto en el derecho de patentes.

El 11 de marzo de 2020, la Organización Mundial de la Salud (OMS) declaró a la crisis del virus COVID-19 (acrónimo del inglés coronavirus disease 2019) como una pandemia, ${ }^{1}$ en un momento en el que había detectados más de 100 mil contagios y reportadas más de 4 mil muertes en 110 países alrededor del mundo. Para finales de noviembre del mismo año, la pandemia superó los 58 millones de contagios y casi 1.400 .000 fallecidos. $^{2}$

La República Argentina no fue ajena a esta crisis. Como medidas preventivas adoptadas por el Poder Ejecutivo Nacional, el 12 de marzo de 2020, por medio del Decreto 260/2020, se prorrogó por el plazo de un ańo la emergencia sanitaria declarada por la Ley $27541^{3}$ y, pocos días después, se dictó el Decreto 297/2020 estableciendo el Aislamiento Social Preventivo y Obligatorio (ASPO) en todo el país, el cual fue sucesivamente prorrogado y modificado por los decretos 325/2020, 355/2020, 408/2020, 459/2020, 493/2020, 520/2020, 529/2020, 576/2020, 603/2020, 641/2020, 677/2020, 714/2020, 754/2020, 790/2020, $795 / 2020$, entre otros. ${ }^{4}$

1 La OMS define "pandemia” como "la propagación mundial de una nueva enfermedad". Disponible en: https://www.who.int/csr/disease/swineflu/frequently_asked_questions/pandemic/es/.

2 Para seguir la evolución de contagios y fallecimientos a nivel global discriminado por país. Disponible en: https://www.elmundo.es/ciencia-y-salud/salud/2020/03/02/5e5cd4ebfc6c83632e8b4644.html.

3 Ley 27541 de Solidaridad Social y Reactivación Productiva en el Marco de la Emergencia Pública "Artículo $1^{\circ}$ - Declárase la emergencia pública en materia económica, financiera, fiscal, administrativa, previsional, tarifaria, energética, sanitaria y social, y deléganse en el Poder Ejecutivo nacional, las facultades comprendidas en la presente ley en los términos del artículo 76 de la Constitución Nacional, con arreglo a las bases de delegación establecidas en el artículo $2^{\circ}$, hasta el 31 de diciembre de 2020”. Disponible en: http://servicios.infoleg. gob.ar/infolegInternet/anexos/330000-334999/333564/norma.htm.

4 Toda la normativa pertinente se encuentra disponible en el "Digesto Jurídico Emergencia 
No hace falta hacer una investigación exhaustiva para advertir que una situación sin precedentes como esta no solo ha tenido importantes consecuencias económicas y sanitarias, sino también jurídicas. El hecho de que actualmente no existan pruebas de la existencia de tratamientos efectivos contra el coronavirus tiene un impacto en el derecho a la salud y a la vida de las personas y en particular del paciente. ${ }^{5}$

No obstante la inexistencia de un fármaco o tratamiento que sea efectivo según los parámetros de la OMS, la carrera por la vacuna del coronavirus está avanzando a un ritmo nunca antes visto. A poco más de siete meses de que la OMS declarara la pandemia, ya hay 183 candidatas para tratar el COVID-19, ${ }^{6}$ de las cuales 143 se encuentran en fase preclínica, ${ }^{7} 18$ en fase $1,{ }^{8} 10$ en fase $1 / 2,{ }^{9}$ 2 en fase $2,{ }^{10}$ y 10 en fase $3 .{ }^{11}$ Actualmente, ninguna de las candidatas para vacuna del coronavirus se encuentra en la fase clínica $4 .{ }^{12}$ Es una carrera por la vacuna

Sanitaria”. Disponible en: http://s3.arsat.com.ar/cdn-bo-001/banner/Digesto_Juridico_ Emergencia_Sanitaria_23-10-2020.pdf.

$5 \mathrm{Al}$ momento de escribirse este artículo no había tratamiento ni vacuna que hayan superado los parámetros de la OMS. Disponible en: https://www.who.int/es/emergencies/diseases/ novel-coronavirus-2019/question-and-answers-hub/q-a-detail/q-a-coronaviruses.

6 Catálogo completo disponible en la página Web de "CAEME Innovación para la Salud". Disponible en: https://www.caeme.org.ar/vacunas-candidatas-covid-19/\#.

$7 \quad$ Ibídem. "Los estudios preclínicos usan sistemas de cultivos de tejidos o cultivos de células y pruebas en animales, que pueden ser ratones o monos, para evaluar la seguridad de la vacuna candidata y su capacidad imunógena, o capacidad de provocar una respuesta inmunológica”.

8 Ibídem. La Fase 1 consiste en la "introducción inicial de un nuevo IFA en seres humanos para determinar su metabolismo, acciones farmacológicas, efectos secundarios con dosis crecientes y, si fuera posible, de obtener evidencia temprana sobre la eficacia. Incluye el estudio de variaciones entre sub-poblaciones e interacciones con ingesta de alimentos $\mathrm{u}$ otros fármacos. Estos estudios fundamentan el uso del producto en las fases sucesivas. Típicamente, los estudios de Fase I son monitoreados muy cercanamente y pueden ser llevados a cabo en sujetos voluntarios sanos o en alguna ocasión en pacientes".

9 Ibídem. No hay diferencias en su definición con la Fase 1.

10 Ibídem. En la Fase 2 "se determinan la eficacia y la seguridad de diferentes rangos de dosis. De ser posible, también, se establecen las relaciones dosis-respuesta, con el objeto de obtener sólidos antecedentes para el diseño de estudios terapéuticos ampliados (Fase III)”.

11 Ibídem. La Fase 3 consiste en "estudios realizados en grandes y variados grupos de participantes con el objetivo de determinar tanto el balance beneficio-riesgo a corto y largo plazo de la o las formulaciones propuestas como el valor terapéutico relativo de manera general. Se exploran el tipo y perfil de las reacciones adversas más frecuentes y las características especiales del IFA como, por ejemplo, las interacciones clínicamente relevantes y los factores modificatorios principales del efecto, tales como la edad, etc.".

12 La fase 4 es la última y se la realiza una vez aprobada la droga para su comercialización. La fi- 
que ha permitido demostrar la sofisticación -y la importancia- del desarrollo científico argentino, teniendo en cuenta que la sustancia activa de una de las candidatas que se encuentran en fase 3 -la vacuna desarrollada por la Universidad de Oxford y el laboratorio AstraZeneca- está siendo producida en Argentina por el laboratorio mAbxience, en conjunto con el laboratorio mexicano Liomont, previéndose una producción de entre 150 y 250 millones de dosis para distribuir en Latinoamérica.

Introducidos ya en el contexto, estamos en condiciones de vincularlo con el derecho de la propiedad intelectual, en particular, el derecho de las patentes. La incidencia de la pandemia en el régimen de la Ley 24481 no tiene que ver solamente en su aspecto sustancial, sino también en el formal o procedimental.

En cuanto a lo sustancial porque, como veremos, se puede encuadrar la posibilidad de patentar fármacos contra el COVID-19 conforme la regulación legal, otorgando al titular de la patente un derecho subjetivo de propiedad sobre esta. Derecho patrimonial que no puede ser analizado de forma aislada, sino a la luz del contexto en el cual se ejerce, el interés público que conlleva la lucha contra la pandemia y el ejercicio de otros derechos humanos contenidos en el bloque de constitucionalidad. Para esto, el legislador ha previsto ciertos institutos en la ley que permiten conciliar el derecho del titular de la patente reconocido en el artículo 17 de la Constitución Nacional de ser "propietario exclusivo de su obra, invento o descubrimiento, por el término que le acuerde la ley", con otros derechos igualmente constitucionalizados y también con ciertas prerrogativas estatales en la materia. ${ }^{13}$

$\mathrm{Y}$ en lo referente al aspecto formal, al haber sido afectado el procedimiento para la obtención de una patente de invención ante el Instituto Nacional de la Propiedad Intelectual (INPI) por las medidas de prevención y aislamiento social

nalidad de los estudios durante este estadio es analizar nuevos usos sobre nuevos individuos, los efectos en el largo plazo y cómo las distintas personas reaccionan ante diferentes dosis. El desarrollo y el proceso de autorización de comercialización de un nuevo producto farmacéutico generan miles y miles de páginas de información correspondiente a los estudios preclínicos, los estudios clínicos y los estudios de fabricación. Toda esta información es confidencial y, una vez recopilada y analizada, es enviada a los organismos oficiales encargados de otorgar la autorización de comercialización de productos farmacéuticos. Ver Sánchez Echagüe (2007, p. 177).

13 El paradigma derechos versus derechos supone repensar los principios, reglas e institutos propios del derecho administrativo según este modelo, siendo este paradigma el equilibrio del poder entendido como el conjunto de prerrogativas que persiguen el reconocimiento de derechos y, por tanto, el concepto es el de derechos versus otros derechos. Ver Balbín (2018, p. 36). 
dispuestas por el Poder Ejecutivo Nacional se ha visto afectado al no poder iniciar o proseguir las solicitudes de manera presencial. En este contexto es que el INPI generó una mesa de entradas virtual, ampliando la ejecución de trámites de las áreas de Asuntos Legales, Transferencia de Tecnología, Marcas y Patentes, pudiendo de este modo el usuario realizar los trámites de manera remota desde cualquier parte del territorio nacional. ${ }^{14}$

El derecho de la propiedad industrial, tal y como ha sido enunciado en reiteradas ocasiones por la doctrina nacional, tiene un rol preponderante en el desarrollo técnico-científico de cualquier país, incentivando la inversión y el espíritu innovador. Esto incluye a la investigación en materia sanitaria, más específicamente la epidemiológica, que será la solución a la crisis que actualmente se transita a nivel mundial.

Pero el derecho que otorga la obtención de una patente no puede tomarse en forma aislada, máxime cuando se encuentra comprometido el orden público sanitario y la sociedad está inmersa en un contexto de emergencia; nos coloca en una posible situación de colisión de derechos, como referimos más arriba en esta introducción al tema.

En los párrafos subsiguientes estableceremos la conexión entre la crisis del COVID-19 y la aparición del o los fármacos que pueden combatirlo con los institutos regulados en la Ley 24481 de Patentes de Invención y Modelos de Utilidad y sus modificatorias, su evolución desde que se sancionó la derogada Ley 111, en especial lo reglado en cuanto a la posibilidad de patentar fármacos, y la licencia obligatoria del artículo 45 de la ley actual.

\section{El patentamiento de fármacos. Generalidades}

Empecemos encuadrando el derecho subjetivo que obtiene el titular de una patente (por ende, también de la patente de un fármaco). Encuadran al derecho de autor (propiedad intelectual propiamente dicha o en sentido estricto) y al derecho de la propiedad industrial (patentes, modelos y marcas) (Causse, 2017 p. 411).

Entonces -como derecho subjetivo enmarcado dentro del derecho de la propiedad industrial-, el derecho del titular de la patente del fármaco es un derecho de propiedad patrimonial que no encaja en la división dicotómica entre derechos reales o personales manifiesta en el Código Civil y Comercial (artículos 724 y

14 La información está disponible en "Portal de Trámites” de la página web oficial del Instituto Nacional de la Propiedad Intelectual. Disponible en: https://www.argentina.gob.ar/noticias/portal-de-tramites-nuevas-funcionalidades. 
1882) (Causse, 2017 p. 411). ${ }^{15}$ "Patrimonial" en el sentido constitucional de la expresión conforme a la jurisprudencia de la Corte Suprema de Justicia de la Nación, más extensivo que la mera noción del "derecho real de dominio". ${ }^{16}$ Además de patrimonial, estamos hablando de un derecho de oponibilidad absoluta o erga omnes, otorgando facultades exclusivas al titular de la patente, viéndose expresado esto en las acciones que tutelan este derecho.

No es una caracterización meramente teórica. Por un lado, el hecho de conceptualizar los derechos de propiedad intelectual como derechos patrimoniales les confiere la protección que el ordenamiento jurídico le reconoce al derecho humano de propiedad, siendo las limitaciones a este excepcionales y de interpretación restrictiva. Y, por el otro, la significación económica que estos derechos tienen; en este sentido, los argumentos utilitaristas en materia de patentes encuentran su fundamentación básica en la necesidad de desarrollar los incentivos que resulten necesarios para mantener un nivel de actividad inventiva socialmente deseable (Iannello, 2013a, p. 56).

Causse (2017, p. 411) señala que todos los derechos que componen el género de derechos de propiedad intelectual "recaen sobre objetos inmateriales" (corpus misticum), que suelen materializarse en bienes corporales (corpus mechanicum), sirviendo como medio para percibirlo. En este caso, el objeto es la patente, que considerada en sí misma es una entelequia, un título otorgado por el Estado a través del órgano competente para hacerlo al creador de una invención, cuando esta reúna los requisitos exigidos por ley y que no se encuentre entre las causales de exclusión o prohibición de patentabilidad.

En cambio, el corpus mechanicum (el medio) será la vacuna que se ha patentado. La OMS define "vacuna" como "cualquier preparación destinada a generar inmunidad contra una enfermedad estimulando la producción de anticuerpos". ${ }^{17}$

15 Si bien son patrimoniales y absolutos, los derechos intelectuales no encuadran dentro de los derechos reales, ya que en estos su objeto es la cosa (solo excepcionalmente puede consistir en un bien como lo indica el artículo 1882 del Código Civil y Comercial). Tampoco son derechos personales, pues estos son de efecto relativo y las facultades que de ellos dimanan se asientan en una relación jurídica que vincula a personas determinadas. En la doctrina "se ha sostenido la tesis de que los derechos intelectuales (iura in re intllectuali) constituyen una categoría distinta de los derechos reales y personales. No obstante, ello no propugna una identidad de régimen" (Causse, 2017, p. 412).

16 Corte Suprema de Justicia de la Nación, Pedro Emilio Bourdieu c/Municipalidad de la Capital. La CSJN definió a la propiedad como "todos los intereses que un hombre puede poseer fuera de sí mismo, fuera de su vida y de su libertad” (Fallos: 145:307).

17 OMS, Vacunas. World Health Organization. Disponible en: https:/www.who.int/topics/ vaccines/es. 
Hay que aclarar que no se viola este derecho de propiedad cuando, de acuerdo a la legislación, válidamente sancionada y ajustada a derecho y de modo que no resulte arbitrario, la patente no es concedida al solicitante. En cambio, sí podría invocarse el derecho humano a la propiedad si un titular de una patente es privado injustamente del bien o se le afecta su pleno goce y disfrute (Schötz, 2013c, p. 137).

Con los conceptos precedentes, cabe preguntarse: ¿Es una vacuna susceptible de ser patentada y conferirle al titular los derechos y obligaciones que especifica la Ley 24481? La respuesta es sí. Al derogar el actual régimen legal de patentes la vieja Ley 111 del año 1864, se eliminó su artículo 4, que prohibía expresamente la posibilidad de patentar composiciones farmacéuticas (por ende, las vacunas, al estar comprendidas dentro del género de los fármacos). Ergo, si es materia patentable una vacuna, a los fines de dar cumplimiento con los recaudos que el artículo 4 de la Ley de Patentes exige para que esta pueda patentarse, podremos conceptualizarla como un producto que constituye creación humana que permite transformar la materia para su aprovechamiento por el hombre (invención), siendo, a su vez, novedosa y entrañando actividad inventiva y con aplicación industrial.

Este es un punto de especial importancia en el tema que nos convoca, máxime cuando la patente es un medio para incentivar la innovación, ya que sin ella y sin un mercado, no habría investigación privada. Siguiendo esta lógica, el sistema lleva a reclamar la afectación de la inversión hecha en vista a un futuro retorno. Si el sistema de patentes promueve una recompensa como contraprestación por el desarrollo de vacunas, esa inversión es una propiedad para su titular. Sobre todo si se la ha escogido como el medio para promover la innovación (Schötz, 2013c, p. 138).

A continuación, veremos la evolución sobre la posibilidad de patentar vacunas en Argentina, los requisitos que actualmente la ley le exige a una vacuna para poder ser patentada, el procedimiento a seguir y los cambios que este ha sufrido durante el Aislamiento Social Preventivo y Obligatorio decretado durante la emergencia sanitaria provocada por el coronavirus, y los derechos que la ley otorga al titular de la patente de la vacuna.

\subsection{Evolución}

En los albores de la Edad Moderna, cuando se concedieron las primeras patentes con mecanismos mucho menos sofisticados que los que tenemos actualmente, tales reconocimientos se otorgaban con una finalidad retributiva al inventor por su aporte a la sociedad. 
Posteriormente, se añadió el fundamento de evitar que los inventores dieran publicidad a sus invenciones y así evitar que permanecieran ocultas. Además, cabe añadir que el hecho de un privilegio en la explotación del titular de la patente sirve de incentivo para que otros intenten llegar a resultados similares por recursos y medios propios e innovadores, generando un círculo virtuoso en el desarrollo inventivo de la sociedad.

Me atrevo a decir que hoy no hay dudas de la importancia que tiene la existencia de las patentes para incentivar la investigación y el desarrollo, y en la promoción y aplicación del conocimiento técnico y científico, máxime en materia farmacológica (y epidemiológica, como herramienta más eficaz de combatir el coronavirus). Así lo expresaba a mediados de los ańos 80, el profesor de la Universidad de Múnich, F. K. Beier (1986):

El derecho exclusivo de patente no se limita a fomentar la disposición de las empresas a invertir en nuevos desarrollos -es decir que no actúa sólo en la fase de investigación y desarrollo del proceso innovador-, sino que también fomenta decisivamente la aplicación y la divulgación del conocimiento técnico, que es lo que a la larga resulta de interés para el progreso técnico. Al asegurarse el uso exclusivo de la invención para una sola persona -el titular de la patente-, esta idea técnica intangible, accesible a todos una vez revelada, se convierte en un bien negociable, un objeto del tráfico jurídico y comercial. De este modo, la invención puede explotarse sin riesgo, y no sólo en el establecimiento propio: puede transferirse y darse en licencia a otros; el progreso técnico encarnado en ella se difunde y la patente se convierte en un importante instrumento de la transferencia de tecnología. (p. 11)

Pero pareciera que esto no fuera así para el legislador argentino a finales del siglo XIX al reglamentar el derecho de propiedad intelectual, al menos en cuanto a la consideración de los fármacos como materia patentable se refiere. En palabras de Pedro Chaloupka (1987, p. 34), la Ley 111 se sancionó con un espíritu de in dubio contra patentem, el cual luego se vio reflejado en las decisiones de los tribunales que tuvieron que resolver sobre la materia. Así, el artículo 4 de la ley derogada establecía que no eran patentables las "composiciones farmacéuticas".

La Organización Mundial de la Propiedad Intelectual (OMPI), en OMPI/ ALADI/81/4/4, precisa los conceptos de "composición" y "compuesto". "Composición o mezcla de sustancias" es la acción y efecto de componer; por analogía se emplea para denominar químicamente a la mezcla de dos o más compuestos con o sin aditivos o de un compuesto y aditivos. Respecto al "compuesto", quí- 
micamente se define como una sustancia que se genera al hacer reacción la sustancia o varias sustancias entre sí.

Chaloupka hace un muy completo repaso de la jurisprudencia que ha sostenido la constitucionalidad del precepto prohibitivo de la Ley 111. En el año 1970, la Corte Suprema de Justicia de la Nación, en autos American Cyanamid Company c/Unifa SACI, s/usurpación de patente de invención, se pronunció por la constitucionalidad de la prohibición contenida en la Ley 111 sobre la patentabilidad de las composiciones farmacéuticas. En este caso, la actora era titular de una patente de un método para producir un antibiótico (dimetilclortetraciclina) y entabló una demanda contra el laboratorio Unifa por usarla en la producción de un fármaco, importada de Italia, donde se habría fabricado con el procedimiento patentado por Cyanamid. Frente a esto, Unifa declaró ignorar el procedimiento por el cual su proveedora en Italia obtuvo el antibiótico, negando que hubiera sido aquel el patentado por Cyanamid y señalando que la patente de un procedimiento no podía intentar enervar la legitimidad del producto obtenido. La Corte se pronunció por la constitucionalidad de la prohibición de patentar composiciones médicas de la Ley 111; el razonamiento puede resumirse de la siguiente manera: 1) el tópico se proyecta en el plano supremo del interés de la salud al igual que lo hizo la entonces ley de patentes francesa de 1844, que inspiró al texto argentino, la cual partía de la base de que era preferible distribuir el medicamento en beneficio público que reconocerle el privilegio a su inventor; 2) la patentabilidad de los procedimientos para la obtención de fármacos debe analizarse con prudencia, porque podría desvirtuarse la prohibición del artículo 4 de la Ley $111 ; 3$ ) la prohibición legal comprende la composición en sí misma, la proporción de los componentes de esta, e incluso la farmacopea veterinaria; 4) la prohibición no es inconstitucional, pues todos los derechos consagrados en la Constitución Nacional son susceptibles de ser razonablemente reglamentados, tratándose en el caso de los inventos de fármacos, pudiendo resultar perjudiciales a los altos objetivos del Estado (Chaloupka, 1987, p. 60).

A raíz de esta interpretación, los inventores de productos farmacéuticos se vieron limitados a solicitar el patentamiento de procedimientos para obtener aquellos, pero no los productos en sí, más allá de que cumplieran con los requisitos de patentabilidad. Se trataba de los denominados "procesos análogos", aquellos que contienen un nuevo producto, pero cuyos pasos ya resultan conocidos (Bensadon y Sánchez Echagüe, 2008, p. 59).

Pero esta postura por la constitucionalidad del precepto prohibitivo del patentamiento farmacológico no fue pacífica durante la vigencia de la ley derogada. Jorge R. Vanossi sostuvo que, en primer lugar, la prohibición violaba el artículo 
17 de la Constitución Nacional, que establece que todo inventor es propietario exclusivo de su invento por el término que dicta la ley (Laquis, s.f.). A este primer argumento, Chaloupka (1987) ańade que la propia ley establecía que los nuevos descubrimientos o invenciones "en todos los géneros de la industria" confieren a sus autores el derecho exclusivo de explotación (artículo 1). Y, en segundo lugar, Vanossi señalaba que era inadmisible el hecho de que la ley de patentes excluyera en su totalidad un género cualquiera de inventos en función de la rama industrial a la que perteneciera, más allá de que sí puedan ser tratados con un criterio diferenciado sin tener que llegar a la prohibición (Chaloupka, 1987, p. 64).

Como bien señalara Ernesto O'Farrell (1988, p. 37), en la época en la que se dictaron la Ley 111 y la ley francesa (1864 y 1844, respectivamente), la ciencia química no tenía ni de lejos el nivel de sofisticación que actualmente tiene y a la farmacología ni siquiera podía considerársela una ciencia. En efecto, dice A. R. Vázquez (1991, p. 42), en ese momento histórico las recetas eran las denominadas "magistrales" y los boticarios las componían sobre la base de las prescripciones efectuadas por los doctores, por ende, si esas recetas consistían en mezclar componentes extraídos - la mayoría de las veces- de la naturaleza, difícilmente pudieran ser patentables, porque impediría que otros boticarios pudieran realizar duplicados de dichas combinaciones. Probablemente, de allí venga la prohibición de patentar composiciones farmacéuticas, no porque fueran medicamentos, sino porque eran simples mezclas. Situación que en el siglo XX fue cambiando, lo cual indefectiblemente se vería reflejado en la legislación supranacional y, posteriormente, en la nacional.

Así, la industria químico-farmacéutica ha experimentado un desarrollo espectacular, en especial a partir de la década de 1930, cuando se pasa de un método de producción en el que los medicamentos se elaboraban en forma artesanal en las mismas farmacias a otro en el que la producción es emprendida a gran escala por establecimientos industriales que cuentan con una vasta dotación de recursos humanos, tecnológicos y económicos, y en los que las especialidades medicinales son sometidas a sendos procesos de control de seguridad, eficacia y calidad. ${ }^{18}$

Posteriormente, empezaron a sumarse argumentos eficientistas justificantes de los derechos de propiedad intelectual basados en su impacto económico. Esto tuvo especial importancia para el caso de la industria farmacéutica porque: 1) es un sector de la industria que por su propia naturaleza tiene un rol fundamental en la investigación y con costos elevados; 2) sencillez en la imitación de las invenciones y bajo costo, lo cual genera incentivos a la inversión (nótese que las

18 Ver Panadeiros (1991, p. 57). 
especialidades medicinales innovadoras requieren una inversión elevada, pero su copia es sencilla y barata); 3) la competencia entre las empresas gira en torno a la innovación, por lo que las ganancias dependen en gran medida de esta.

Estos estudios económicos concluyeron en que la falta de patentes en la industria farmacéutica reduciría la tasa de gasto en investigación y desarrollo en mayor proporción que en otras industrias. ${ }^{19}$ Es en función de estos especiales requisitos de la industria farmacológica que resultan los incentivos a la innovación para asegurar la actividad inventiva, fundamento del sistema de patentes (Iannello, 2013, p. 29). A punto tal que, sobre la necesidad de protección de la patente en la industria farmacéutica, unos años más adelante, Peter Kolker (1996) (miembro del Comité de Propiedad Intelectual de la Federación Internacional de la Industria del Medicamento), citando a Silberston (1987), señalaba que dicha industria "es totalmente dependiente de la protección de patentes" porque "es la exclusividad que otorga la patente la que protege el enorme riesgo de inversión en investigación y desarrollo, al brindar al innovador la oportunidad de obtener una compensación por un período de tiempo limitado" (p. 15).

Los clamores de la doctrina por una reforma de la legislación en esta materia se vieron reflejadas en la elaboración de una clasificación de las tendencias que se dieron en la reforma legislativa: el aislamiento y la armonización. ${ }^{20}$ El "aislamiento" promovía el concepto de que las normas de cada nación debían moldearse según su situación particular. En cambio, la "armonización" se basa en el establecimiento de estándares mínimos a nivel supranacional que deben respetarse por las legislaciones internas que adhieran a estos, teniendo en cuenta el contexto de una creciente interdependencia y necesidad de promover la innovación. Al momento de elaborarse esta teoría, ya había un proyecto de reforma del Poder Ejecutivo (53/1993) que, a criterio de la doctrina, seguía la tendencia de la armonización. ${ }^{21}$

Hubo que diseñar un sistema de protección de la patente farmacéutica en la que: 1) el período de vigencia de las patentes fuera lo suficientemente prolongado como para que su titular pudiera obtener una compensación por su invención y en el cual el innovador pudiera estimar que valdría la pena asumir el riesgo que implica el proceso de investigación y desarrollo (nótese la importancia que tiene esto en el día de hoy en el campo de la medicina en cuanto a lo referido al desarrollo de la vacuna para el coronavirus); 2) se cubra la invención que es objeto de la patente (v.gr. la vacuna); 3) tutela judicial efectiva para el titular de la patente,

19 Ver Panadeiros (1991, p. 54).

20 Así lo conceptualiza Rozansky (1994, p. 38).

21 Ibídem. 
la posibilidad de reivindicarla mediante procedimientos eficaces y la habilitación de las vías recursivas o impugnatorias pertinentes (detención y sanción de la infracción) que surgen de su oponibilidad erga omnes.

Importante en este aspecto fue el Acuerdo General sobre Aranceles Aduaneros y Comercio - Acuerdo sobre los Aspectos de los Derechos de Propiedad Intelectual Relacionados con el Comercio (GATT-ADPIC) que establecieron disposiciones mínimas a ser incluidas en las leyes de patentes de los países miembros de la Organización Mundial del Comercio (OMC), la cual entró en vigor el 1 de enero 1995. El Acuerdo ADPIC fue aprobado por Argentina el 7 de diciembre de 1994 por la Ley 24425, con jerarquía supralegal por imperio del artículo 75, inciso 22 de la Constitución. Entre las disposiciones que establece el ADPIC que nos interesan para este trabajo se encuentran: la posibilidad de que los países miembros adopten medidas para proteger la salud pública y aplicar las medidas apropiadas para prevenir el abuso en el ejercicio de los derechos (artículo 8), las cuales deben ser coherentes con las disposiciones del Acuerdo, especialmente lo referido a la materia patentable (artículo 27), limitadas excepciones a la infracción (artículo 30) y el carácter limitado y excepcional de las licencias obligatorias (artículo 31).

Como principios generales del ADPIC (aplicables también a la industria farmacéutica) se puede mencionar que: 1) se establece un piso mínimo de protección exigida, pudiendo los países miembro en sus legislaciones internas aumentar el nivel de protección de la propiedad intelectual, pero no disminuirla; 2) la igualdad de trato entre sus nacionales con los de los demás miembros en cuanto a la protección de su propiedad intelectual (artículo 3); 3) toda ventaja, favor, privilegio o inmunidad que conceda un miembro a los nacionales de cualquier otro país se otorgará inmediatamente y sin condiciones a los nacionales de todos los demás miembros (artículo 4). Todos estos principios deben interpretarse armónicamente con las excepciones mencionadas en el párrafo anterior acerca de la protección de la salud pública y la prevención del abuso del derecho.

Pero quizás lo más relevante del articulado del instrumento internacional, al menos a los efectos de este trabajo, sea que, conforme surge de la letra del artículo 27 del ADPIC, se pueda concluir que los productos farmacéuticos son patentables para este Acuerdo ratificado por Argentina; considerando que en el referido artículo establece que las patentes podrán obtenerse por todas las invenciones, ya sean productos o procedimientos, en todos los campos de la tecnología.

El Poder Ejecutivo Nacional reglamentó el ADPIC (Ley 24425) y el Convenio de París (Ley 17011) por el Decreto 621/1995, en conjunción con la entonces vigente Ley 111. El problema se presenta al darse la situación de tener vigente un 
tratado internacional con sus normas programáticas reglamentadas que permite patentar fármacos y una ley nacional también vigente que lo prohíbe (artículo 4 de la Ley 111). ¿Cuál prevalece? La Corte Suprema ha resuelto que cuando la Nación ratifica un tratado firmado por ella con otro Estado, se obliga internacionalmente a que sus órganos administrativos y jurisdiccionales apliquen aquel tratado en los supuestos que este contemple, siempre que contenga descripciones suficientemente concretas de tales supuestos de hecho que hagan posible su aplicación inmediata. ${ }^{22}$

Esta necesidad de dar cumplimiento con la manda constitucional de adecuar las leyes de la nación a los tratados de jerarquía supralegal que surge del artículo 75 , inciso 22 de la Constitución Nacional claramente potenciaron los argumentos en favor de la reforma, lo que llevó a que se sancionara la Ley 24481.

La nueva legislación trajo varias innovaciones, la que más nos interesa es la inclusión de la patentabilidad de las invenciones de productos farmacéuticos. Pero ¿cómo se solucionó el plazo de vigencia para estas patentes? Hay que distinguir según se trate de patentes de procedimientos para la obtención de un fármaco o patentes de un producto farmacéutico. Las referidas a procedimientos eran patentables bajo la Ley 111 y lo continúan siendo por aplicación del principio de no regresividad en la protección del artículo 65, inciso 5 del ADPIC, que prohíbe las modificaciones que los países miembros introduzcan a su legislación doméstica disminuyan la compatibilidad de esta con el Acuerdo (recordar el piso mínimo al que me referí anteriormente). Pero los productos no lo eran por la interpretación que se hacía del régimen anterior, y ahora sí.

Las solicitudes para patentarlos pudieron presentarse desde el 1 de enero de 1995 (artículo 70, párr. 8, inciso a del ADPIC y artículo 101, inciso a del anexo II del Decreto 260/1996), pero no fueron otorgadas hasta pasados cinco años de la publicación de la Ley 24572, modificatoria de la Ley 24841 en el Boletín Oficial (artículo 100, anexo I del Decreto 260/1996), lo que podría denominarse un "Período de Transición para los medicamentos". Esto fue muy criticado por la doctrina (Chaloupka, Padilla, Zuccherino, Mitelman) por demorar injustificadamente la aplicación efectiva de los tratados internacionales ratificados por la República Argentina, que consagraban el derecho a la propiedad intelectual en todas la industria farmacéutica, dejando atrás la interpretación prohibicionista del artículo 4 de la Ley 111 (Rozansky, 1996, p. 139).

Lo que la ley no aclaraba era qué ocurría en ese período de transición de cinco años entre el 1 de enero de 1995 al 24 de octubre de 2000 hasta que pudieran ser

22 Corte Suprema de Justicia de la Nación, Ekmekdjian, Miguel A. c/Sofovich, Gerardo y otros, 7/07/92, LL, 1992-C-543 y ss. 
otorgadas las patentes solicitadas sobre los productos farmacéuticos. La respuesta está en el artículo 101, párr. 3, anexo II del Decreto 260/1996 (que toma como base el artículo 70, párr. 9 del ADPIC), que establece que procede durante la transición el otorgamiento de Derechos Exclusivos de Comercialización (DEC) ${ }^{23}$ durante un período de cinco años o hasta que se conceda o rechace la patente. $\mathrm{Al}$ vencimiento de dicho plazo, se preveía una "licencia compulsiva automática", prohibida por el artículo 31 del ADPIC, autorizando a terceros que estuvieran utilizando el invento sin autorización del titular de la patente a continuar con la explotación contra el pago de una retribución "justa y razonable" (artículo 101, párrs. 3 y 4 del Decreto 260/1996, anexo I).

\subsection{Requisitos de patentabilidad}

Hemos visto el camino que ha tenido que recorrer la ley hasta llegar a la actualidad. Ahora veremos los requisitos que debe cumplir una vacuna para ser considerada "patentable".

El artículo 101, inciso I, ap. B, anexo II del Decreto 260/1996 es claro al reglar que para patentar inventos farmacéuticos, se deben cumplir idénticos requisitos de patentabilidad que los que deben cumplir las demás materias patentables. Es decir, cumplir con el artículo 4, párr. 1 de la Ley 24481 (que toma de base el artículo 27.1 del ADPIC) cuando norma que "serán patentables las invenciones de productos o de procedimientos, siempre que sean nuevas, entrañen una actividad inventiva y sean susceptibles de aplicación industrial”. Analicemos los elementos en cuanto a materia farmacológica se refiere.

"Invención" (artículo 4, inciso a): aquí estamos ante el requisito sustantivo de la materia patentable, al cual luego tendremos que adjetivarlo como novedoso, que entrañe actividad inventiva y tenga aplicación industrial. Un fármaco, ya sea producto (en el caso de la eventual vacuna contra el coronavirus, estamos ante un producto) o procedimiento, constituirá una invención cuando se trate de una "creación humana que permita transformar materia o energía para su aprovechamiento por el hombre". Pareciera que esta creación tiene dos elementos: transformación de la materia o la energía (elemento funcional) ${ }^{24}$ y el fin del

23 Esto no los relevaba en lo absoluto de cumplir con los recaudos de registro, elaboración, fraccionamiento, prescripción, expendio, comercialización, importación y exportación farmacéutica de la Ley 16463 para la autorización de la elaboración y comercialización de estos (artículo 98 de la Ley 24481), teniendo tanto al INPI como a la autoridad sanitaria como autoridades de contralor del cumplimiento de dichos recaudos.

24 Funcional en el sentido causa-efecto, el de generar un cambio en el mundo externo al actuar. 
aprovechamiento por el hombre (elemento final). ¿Encuadra aquí una vacuna? Evidentemente. Transforma ciertos compuestos químicos en una sustancia activa que tiene por objeto generar anticuerpos en el ser humano al ser introducida ya sea por inyección o inhalación. Hay un elemento funcional que es la composición farmacéutica que contiene la vacuna y un elemento final consistente en la generación de anticuerpos en el ser humano.

Tal y como lo ha señalado doctrina anteriormente citada, se trata de invenciones cuya generación y desarrollo requiere de importantes inversiones, pero cuya reproducción es relativamente sencilla y poco onerosa. Así es el caso de la vacuna para el COVID-19: actualmente, 183 candidatas -a casi un año de comenzado el brote- tienen que atravesar múltiples filtros preclínicos y clínicos con inversiones multimillonarias y, a su vez, la previsión de producir cientos de millones de dosis cuando alguna o algunas de ellas logren superar todas las fases, justamente por la facilidad de reproducción.

Esto se ve reflejado en los caracteres particulares y distintivos que la industria farmacéutica presenta: 1) en su desarrollo juega un papel fundamental la investigación, dado que esta en sí misma busca mejorar la salud humana, lo que hace también a una mirada social porque mejora la salud pública a través de un proceso de experimentación, "falseable", sujeto a prueba y error, el cual incluso podría tener consecuencias negativas para la salud; 2) la organización de la investigación científica y técnica, que lo vemos reflejado en el sistema de fases preclínicas y clínicas, punto enunciado en la introducción de este texto; 5) implica un enorme esfuerzo humano e involucra el desembolso de cuantiosos recursos económicos; 4) vulnerabilidad a la imitación, su sencilla reproducción, de lo que se deriva su último carácter; 5) los estrictos controles que impone la Administración Pública sobre ellos, máxime cuando está en juego un bien colectivo como la salud pública (Zuccherino y Mitelman, 1994, pp. 88-89).

La importancia de los rigurosos controles de la administración pública excede el ámbito administrativo o de la regulación del INPI. El Código Penal Argentino, en su Libro Segundo, Título VII (Delitos contra la Seguridad Pública), contiene en su Capítulo IV tipos penales vinculados con la cuestión referidos a delitos contra la salud pública como bien jurídico protegido en los artículos 200, 201, 203, 204, 204 bis, 204 ter, 204 quáter, 204 quinquies y 208. Un caso claro de esto durante la pandemia del COVID-19 fue la divulgación del "dióxido de cloro" como método paliativo, lo cual fue desmentido tanto por la OMS como por el Ministerio de Salud de la Nación.

"Novedad" (artículo 4, incisos b y c): de la interpretación del precepto legal podríamos decir que es novedoso todo aquel fármaco o toda aquella vacuna que 
no esté comprendida en el estado de la técnica (inciso b). En el inciso c del mismo artículo la ley define al estado de la técnica como aquel conjunto de conocimientos técnicos que se han hecho públicos antes de la fecha de presentación de la solicitud de patente, o de la prioridad reconocida, mediante una descripción oral o escrita, por la explotación o por cualquier otro medio de difusión o información, en el país o en el extranjero. Es decir, nuestra ley adhiere al concepto de "novedad absoluta" en consonancia con el ADPIC y con el Convenio de París, porque para que un conocimiento técnico forme parte del estado de la técnica debe estar publicitado en el país o en el extranjero al momento de ser presentada la solicitud argentina o de la prioridad invocada (Bensadon y Sánchez Echagüe, 2008, p. 28).

Esto también se vincula con los datos exigidos para obtener la autorización ante la Administración Nacional de Medicamentos, Alimentos y Tecnología Médica (ANMAT) para poder comercializar la vacuna, un tópico no menor que, en determinadas situaciones, puede colocar al solicitante en la situación de revelar datos sobre el fármaco de difícil producción, información que luego puede utilizar en el procedimiento para obtener la patente ante el INPI, como lo desarrollaré en el punto 2.3 de este trabajo.

En este sentido, el ADPIC regula que cuando los Estados establezcan como condición para aprobar la comercialización de productos farmacéuticos la presentación de pruebas u otros datos no divulgados cuya elaboración suponga un esfuerzo considerable, deberán proteger esos datos contra todo uso comercial desleal y contra toda divulgación, excepto cuando sea necesario para proteger al público o que se adopten medidas para garantizar la protección contra todo uso comercial desleal (artículo 39.3).

Del artículo se desprenden cinco requisitos taxativos para la protección de los datos requeridos por la autoridad pública para aprobar la comercialización: 1) que se trate de datos exigidos y presentados como condición para aprobar la comercialización de productos farmacéuticos o químicos agrícolas; 2) que, justamente, el objeto sea un producto farmacéutico o químico agrícola; 3) que utilicen nuevas entidades químicas, que en el ámbito específico de los fármacos que incluyen un principio activo cuya comercialización no haya sido previamente aprobada por la autoridad sanitaria del país; 4) que se trate de datos de pruebas u otros datos no divulgados; 5) que la elaboración de esos datos suponga un esfuerzo considerable, entendido como aquellas "actividades de producción de datos que demandan un esfuerzo de carácter no habitual y que resultan significativamente extensas en su alcance y duración" (Zuccherino y Mitelman, 1994, p. 163). 
Con relación a los datos probatorios para la contratación de vacunas para el coronavirus, el 29 de octubre de 2020 se aprobó en la Cámara de Senadores de la Nación un proyecto que venía con media sanción de la Cámara Baja presentado por el diputado Máximo Kirchner, declarando de interés público la investigación, desarrollo, fabricación y adquisición de las vacunas destinadas a generar inmunidad adquirida contra el COVID-19, como así también los medicamentos, tratamientos y otras tecnologías aplicables en el marco de la emergencia sanitaria establecida por la Ley 27541 y prorrogada por el Decreto 260/2020, sus modificatorias y normativa complementaria en virtud de la pandemia declarada por la OMS (artículo 1 del proyecto sancionado).

Recordar que si bien se protegen los datos exigidos para la comercialización en virtud del artículo 39.3 del ADPIC, el mismo artículo reconoce una excepción a la regla cuando "sea necesario para proteger al público", y así lo trata el proyecto sancionado por la Cámara Alta, aún sin promulgar por el Poder Ejecutivo.

Entre los aspectos más relevantes del proyecto podemos enumerar los siguientes: ${ }^{25}$

1) Se faculta al Poder Ejecutivo Nacional a que, a través del Ministerio de Salud, pueda incluir en los contratos que celebre y en la documentación complementaria para la adquisición de vacunas destinadas a generar inmunidad adquirida contra el coronavirus, cláusulas o acuerdos de confidencialidad acordes al mercado internacional de las vacunas, de conformidad con las leyes de Acceso a la Información Pública (Ley 27275), de Derechos del Paciente (Ley 26529), y normas concordantes, complementarias y modificatorias (artículo 5).

2) El adquirente de vacunas contra el coronavirus debe presentar a la ANMAT a los efectos de la intervención de su competencia la información o dossier de las vacunas que acrediten la eficacia e inocuidad de las mismas y deben ser autorizadas por el Ministerio de Salud en un plazo máximo de 30 días, previo a su uso en la población, en la medida que tengan aprobación por parte del registro pertinente o autorización de comercialización en los países del Anexo I de la Ley de Confidencialidad (24766). ${ }^{26}$ Caso contrario se aplicará el proceso de inscripción de medicamentos de origen biológico, de vacunas y radiofármacos de la ANMAT (artículo 8).

3) Los contratos celebrados deberán ser remitidos a la Auditoría General de la

25 Trámite ante el Senado disponible en: https://www.senado.gob.ar/parlamentario/parlamentaria/ordenDelDiaResultadoLink/2020/373.

26 Estados Unidos, Japón, Suecia, Confederación Helvética (Suiza), Israel, Canadá, Austria, Alemania, Francia, Reino Unido de Gran Bretańa e Irlanda del Norte, Países Bajos, Bélgica, Dinamarca, España, Italia. Disponible en: http://servicios.infoleg.gob.ar/infolegInternet/ anexos/40000-44999/41094/norma.htm. 
Nación y a las autoridades de la Comisión de Acción Social y Salud Pública de la Cámara de Diputados de la Nación y de la Comisión de Salud del Senado de la Nación, con los recaudos correspondientes a los fines de respetar las cláusulas de confidencialidad que pudieran incluirse (artículos 9 y 10).

4) Las facultades y autorizaciones que el proyecto establece tendrán vigencia hasta 12 meses posteriores a la finalización de la ampliación de la emergencia sanitaria generada por la pandemia del coronavirus establecida en el decreto 260/20 y sus modificatorias (artículo 11).

5) Las cláusulas o acuerdos de confidencialidad no podrán estar referidos a los aspectos técnicos de la vacuna y no son aplicables a los organismos de control de su seguridad y eficacia (artículo 11).

"Actividad Inventiva" (artículo 4, inciso d): la ley expresa que "habrá actividad inventiva cuando el proceso creativo o sus resultados no se deduzcan del estado de la técnica en forma evidente para una persona normalmente versada en la materia técnica correspondiente". En este sentido, Zuccherino y Mitelman (2008) expresan que la actividad inventiva o "altura inventiva", como otras legislaciones la denominan, "es, probablemente, el requisito más característico a evaluar para determinar la patentabilidad de los inventos" (p. 33).

La anterior legislación hacía referencia al "mérito inventivo" en su artículo 5 al establecer que "las patentes serán acordadas por 5 , por 10 y por 15 años, según el mérito del invento". El mérito hoy no tiene relevancia a los efectos de determinar el plazo de concesión de la patente porque el artículo 35 de la Ley 24484 norma que esta "tiene una duración de 20 años improrrogables, contados a partir de la fecha de presentación de la solicitud", sin distinción de mérito alguno.

No hay que confundirlo con la novedad; esta existe si hay cualquier diferencia entre la invención y el arte previo, le sirve de presupuesto a la actividad inventiva. Lo que aquí se busca determinar es si el fármaco introduce un avance en la tecnología, lo cual está intrínsecamente relacionado con la finalidad del ordenamiento patentario en lo que se refiere a incentivar la investigación y el desarrollo técnico y científico. En este caso, también podríamos ańadir las implicancias que esto tiene en los intereses superiores del Estado en la protección de la salud pública y la vida de las personas en cuanto a la lucha contra el coronavirus se refiere.

Lo cierto es que la ley no da reglas precisas sobre cuándo estamos frente a una actividad inventiva, siendo que esto no es un proceso sencillo, cuestión que, eventualmente, quedará a criterio de la apreciación subjetiva del órgano jurisdiccional. Criterio que no deberá ser muy riguroso, teniendo en cuenta que el hecho de encontrarse reunidos los requisitos de novedad y aplicación industrial da un indicio de la existencia de la actividad inventiva (Zuccherino y Mitelman, 2008, p. 34). 
$\mathrm{Al}$ ser la actividad inventiva una variante con un fuerte componente subjetivo - para evitar posibles análisis arbitrarios-, la doctrina ha elaborado una serie de pasos a seguir para determinar la concurrencia o no de este requisito de patentabilidad en el caso que se trate.

Primero hay que determinar el estado de la técnica al estado de la solicitud (hoy, el estado sería: no hay vacuna o tratamiento para el COVID-19), podría determinarse v.gr. constatando la documentación recolectada por la ANMAT, tal como surge del artículo 8 del proyecto sobre interés público en la contratación de vacunas para el coronavirus anteriormente citado. Determinado el estado de la técnica, se procede a la construcción de una persona ideal, normalmente versada en la materia técnica correspondiente (Zuccherino y Mitelman, 2008, p. 38), en este caso, la farmacológica, v.gr. un laboratorio. Y finalmente, teniendo en cuenta el estado de la técnica (inexistencia de la vacuna) y la persona normalmente versada en la materia técnica correspondiente (el laboratorio), se analiza si el invento no se hubiera deducido en forma evidente para esa persona (Zuccherino y Mitelman, 2008, p. 39).

Independientemente de esta construcción, entiendo que a quien le toque juzgar sobre la concurrencia de la actividad inventiva en la vacuna no le será muy difícil, teniendo en cuenta el riguroso sistema de fases que una vacuna debe atravesar para llegar a ser aprobada, producida en masa, comercializada, distribuida y patentada.

Claramente, estas ponderaciones no son taxativas. Puede tenerse en cuenta también la "satisfacción de un deseo largamente esperado", si no se han logrado avances de relevancia en el área y el invento cambia el estado de las cosas, se entiende que concurre la actividad inventiva (Zuccherino y Mitelman, 2008, p. 40). Esto lo podemos encuadrar en el desarrollo de la vacuna, aunque es discutible que la aparición de la vacuna sea un "deseo largamente esperado", teniendo en cuenta que el desarrollo de las vacunas en epidemias anteriores ha durado años o incluso décadas. Lo cierto es que basta con observar la cantidad de candidatas y la cobertura mediática que se le da al desarrollo y los avances que cada una de ellas está teniendo para poder afirmar que el mundo está esperando esa novedad farmacológica que cambie el estado de las cosas.

También puede considerarse el "fracaso de los otros"; si hay una gran cantidad de vacunas concurriendo y una o varias triunfan donde muchas otras no lograron superar siquiera la fase preclínica, debe considerarse que hay actividad inventiva (Zuccherino y Mitelman, 2008, p. 41).

También, algo que es característico de la industria farmacéutica, como mencioné anteriormente, es la "necesidad de formar un equipo de investigación en 
forma planeada, metódica y prolongada" justamente para la obtención de la vacuna y avanzar en el estado de la técnica (Zuccherino y Mitelman, 2008, p. 41).

Como puede verse, se trata de una cuestión sumamente compleja y relevante con multiplicidad de criterios y parámetros para determinarla.

"Aplicación Industrial" (artículo 4, inciso e): el último requisito para la patentabilidad de la vacuna será su aplicación industrial, que concurre "cuando el objeto de la invención conduzca a la obtención de un producto industrial". A su vez, la ley entiende como comprensivo del término "industria" a "la agricultura, la industria forestal, la ganadería, la pesca, la minería, las industrias de transformación propiamente dichas y los servicios". El invento debe exceder lo meramente teórico, debe conducir a un producto industrial concreto, lo cual muchas veces surge con claridad de la propia descripción del invento al presentar la solicitud (Zuccherino y Mitelman, 2008, p. 41). En la medida en que un agente económico tiene en cuenta dicha aplicación al momento de plantearse la inversión excediendo lo meramente teórico, la expectativa creada, en cuanto derecho exclusivo, constituye para él una propiedad (Schötz, 2013c, p. 139).

En consonancia con esto, el artículo 1 del Convenio de París de Protección de la Propiedad Industrial (Ley 17011) resuelve entender a la propiedad industrial en su aceptación más amplia, aplicándose no solo a la industria y al comercio propiamente dichos, sino también al dominio de las industrias agrícolas y extractivas y a todos los productos fabricados o naturales, v.gr. vinos, granos, tabaco, minerales, etcétera.

Una vacuna está comprendida en este concepto. Tal como mencioné anteriormente, la producción farmacológica requiere un alto nivel de desarrollo tecnológico y científico, requiriendo el desembolso de cuantiosos recursos económicos e implica un esfuerzo humano considerable en su producción.

\subsection{Procedimiento de patentamiento ante el INPI durante el aislamiento social}

$\mathrm{El}$ procedimiento para patentar una vacuna o cualquier fármaco no solo tiene implicancias en la Ley 24481, sino también tiene relevancia constitucional. Así, el artículo 42 de la Constitución Nacional reconoce el derecho de los consumidores y usuarios de bienes y servicios a la protección de su salud, seguridad e intereses económicos; a una información adecuada y veraz; a la libertad de elección; y a condiciones de trato equitativo y digno. Para esto, las autoridades deben proveer la protección de estos derechos y permitir la participación de los consumidores en los organismos de control.

En cuanto el procedimiento ante el INPI, se encuentra regido por la Ley 
24481, artículo 12 y concordantes. Entonces, quien busque obtener la patente sobre el fármaco debe presentar una solicitud ante la Administración Nacional de Patentes del INPI, conforme los requisitos establecidos por la ley y su reglamentación (artículo 12).

Dentro de los mencionados requisitos que deben tenerse en cuenta para la solicitud, la ley establece que a la fecha de presentación el solicitante debe entregar a la Administración Nacional de Patentes la declaración por la cual solicita la patente del fármaco, la identificación del solicitante, una descripción y una o varias reivindicaciones, aunque no cumplan con los requisitos formales establecidos en la ley (artículo 18). Las reivindicaciones definirán el objeto para el que se solicita la protección (v.gr. una vacuna para el COVID-19), debiendo ser claras y concisas. Podrán ser una o más y deberán fundarse en la descripción sin excederla (artículo 22).

Asimismo, el solicitante, para obtener la patente del fármaco, en conjunto con su solicitud o dentro del plazo de 30 días corridos debe cumplir con lo normado en el artículo 19, bajo apercibimiento de que la patente le sea denegada sin más trámite, es decir, acompañar la denominación y descripción de la invención con los planos o dibujos técnicos que se requieran para la comprensión de la descripción, una o más reivindicaciones y un resumen de la descripción de la invención que servirá únicamente para su publicación y como elemento de información técnica.

El fármaco que se busca patentar deberá ser descripto en la solicitud de manera suficientemente clara y completa para que una persona experta y con conocimientos medios en la materia pueda ejecutarlo. Asimismo, deberá incluir el mejor método conocido para ejecutarlo y llevarlo a la práctica y los elementos que se empleen en forma clara y precisa. Los métodos y procedimientos descriptos deberán ser aplicables directamente en la producción (artículo 20).

Cumplidos los requisitos anteriormente enunciados por el solicitante, la Administración Nacional de Patentes realizará un examen preliminar de la solicitud para patentar el fármaco y podrá requerir que se precise o aclare lo que considere necesario o se subsanen errores u omisiones por el plazo de 30 días, bajo apercibimiento de dar por abandonada la solicitud (artículo 24). En este punto podríamos plantear el interrogante de qué ocurriría en el hipotético caso en el que durante el trámite de la patente de una vacuna para el COVID-19, la Administración Nacional de Patentes mande a subsanar alguna omisión y el laboratorio solicitante no cumpla con la subsanación en plazo oportuno ¿Corresponde dar por abandonada la solicitud de un producto tan importante para el cuidado de la salud pública?

Tanto la solicitud de patente en trámite como sus anexos serán confidenciales 
hasta el momento de su publicación dentro de los 18 meses de la presentación de la solicitud, salvo petición en contrario por parte del solicitante (artículos 25 y 26).

Previo pago del arancel, bajo apercibimiento de tenerlo por desistido si no lo hiciese dentro de los 18 meses de la solicitud, la autoridad procederá a realizar un examen de fondo de la solicitud presentada para verificar que se cumpla con todos los requisitos sustanciales que la ley exige. La autoridad puede requerir copia del examen de fondo realizado por oficinas extranjeras examinadoras (v.gr. en caso de que la vacuna ya esté patentada en otro país, como la rusa SPUTNIK $\mathrm{V})$ e informes a investigadores que se desempeñen en universidades o institutos científico-tecnológicos del país (v.gr. CONICET, ANLIS "Dr. Carlos G. Malbrán”), pudiendo, a su vez, el solicitante requerir que el examen se realice en sus instalaciones o laboratorios (artículo 27).

De las observaciones que realice la Administración Nacional de Patentes luego de hacer el análisis de fondo de la solicitud de patentamiento de la vacuna, se correrá traslado al solicitante para que, dentro del plazo de 60 días, haga las aclaraciones que considere pertinentes o presente la información o documentación que le fuera requerida, bajo apercibimiento de tener su solicitud se considerará desistida. No tengo reparos con esta solución, siendo que se trata de una cuestión de fondo acerca de la patente y no meramente formal. Además, cualquier persona (v.gr. alguna asociación de los famosos "antivacunas") podrá formular observaciones fundadas en la falta o insuficiencia de los requisitos legales para su concesión a la solicitud de patentes y agregar prueba documental dentro del plazo de 60 días a contar de la publicación de la solicitud de patentamiento del fármaco (artículos 28 y 29).

Con las medidas de aislamiento, el INPI generó una mesa de entradas online para el inicio y continuación de los trámites por vía digital a través del envío de formularios también en formato digital. Asimismo, se ha ampliado el plexo de trámites disponibles para iniciar de forma virtual y se agregaron nuevas funcionalidades que permiten realizar al usuario, por ejemplo, un seguimiento más detallado de los pagos. ${ }^{27}$ Es más, se permite la realización de trámites correspondien-

27 El INPI se encuentra adscripto a la plataforma para el libramiento de Oficios y su Diligenciamiento por Medios Electrónicos a Organismos Externos (DEOX) del Poder Judicial de la Nación, herramienta dispuesta con carácter obligatorio por la Acordada CSJN 15/2020 para el ámbito de la Justicia nacional y federal, por lo que el único medio de diligenciamiento de oficios judiciales al INPI como organismo público requerido es esa plataforma. Lo que sí pueden realizar por el Portal de Trámites Web INPI en relación a los oficios judiciales que deben librarse por el DEOX es abonar el arancel -cuando tal diligencia conlleve ese carga- y luego adjuntar el comprobante de pago cuando libren el oficio judicial a través del DEOX, toda 
tes a la Dirección de Asuntos Legales, firmarlos y abonarlos de forma online. De esta manera, se pueden tramitar de forma digital registros de poderes, renuncias, pedidos de informes o medidas cautelares y presentación de recursos. ${ }^{28}$

Aprobados todos los requisitos, la Administración Nacional de Patentes procederá a extender el título, sin perjuicio de tercero con mejor derecho que el solicitante y sin garantía del Estado en cuanto a la utilidad del objeto sobre el que recae (artículos 30 y 31). Con la emergencia sanitaria ocasionada por el COVID-19, el INPI ha previsto la generación de Títulos de Patentes de Invención y de Certificados de Modelos de Utilidad en formato digital.

La patente de la vacuna otorgada será de público conocimiento y, para ello, el artículo 32 prevé que la concesión de la patente se publicará en la página web del Instituto Nacional de la Propiedad Industrial. Además, se extenderá copia de la documentación a quien la solicite, previo pago de los aranceles correspondientes (artículo 34).

La patente tiene una duración de veinte ańos improrrogables, contados a partir de la fecha de presentación de la solicitud (artículo 35).

\subsection{Derechos que obtiene el titular de la patente de un fármaco}

El acto mediante el cual el Estado otorga la titularidad de la patente sobre el fármaco o la vacuna implica el reconocimiento de un derecho de propiedad amparado no solo en la Ley de Patentes y en los tratados de jerarquía supra legal, como el ADPIC.

En tal sentido, lo expresa la Constitución Nacional cuando establece en su artículo 17 que "Todo autor o inventor es propietario exclusivo de su obra, invento o descubrimiento, por el término que le acuerde la ley" y el artículo 14, cuando le reconoce a todos los habitantes de la nación el derecho "de usar y disponer de su propiedad".

$\mathrm{Al}$ proteger los derechos conferidos por la patente -"la exclusividad de ejecución de las ideas nuevas y originales" (García Sellart, 2001, p. 162)-, la Ley 24481, en su artículo 8, siguiendo los lineamientos del artículo 28 del ADPIC, reconoce la titularidad del derecho a la patente en cabeza del inventor o sus causahabientes, quienes tienen el derecho de cederlo o transferirlo por cualquier medio lícito y concertar contratos de licencia (artículos 37 y ss.).

Además, la patente de una vacuna, por tratarse de un producto farmacológico, conferirá a su titular el derecho exclusivo de impedir que terceros, sin su

vez que dicha plataforma permite adjuntar ese comprobante al librarse el oficio. Disponible en: https://www.argentina.gob.ar/noticias/portal-de-tramites-nuevas-funcionalidades.

28 Ver: https:/www.argentina.gob.ar/noticias/portal-de-tramites-nuevas-funcionalidades. 
consentimiento, realicen actos de fabricación, uso, oferta para la venta, venta o importación del producto objeto de la patente, sin perjuicio de lo normado en los artículos 36 (terceros respecto a los cuales el derecho que confiere la patente no produce efecto alguno) y 99 (solicitudes de patentes que se encuentren en trámite en la fecha en la que la ley entró en vigor) de la ley.

\section{Solicitud de comercialización y distribución ante la ANMAT}

Así como el Instituto Nacional de la Propiedad Intelectual, a través de la Administración Nacional de Patentes, es el órgano competente para reconocerle al sujeto solicitante la titularidad de la patente y los derechos que esta confiere, en lo referido a la comercialización y distribución de la vacuna es otro el organismo interviniente para autorizarla.

La Administración Nacional de Medicamentos, Alimentos y Tecnología Médica (ANMAT), creada por el Decreto 1490/1992, es el organismo descentralizado con competencias para el control y fiscalización de la calidad y sanidad de los productos, substancias, elementos y materiales que se consumen o utilizan en la medicina, alimentación y cosmética humanas, y de contralor de las actividades, procesos y tecnologías que mediasen o estuviesen comprendidos en dichas materias.

En este sentido, con la finalidad última de la protección de la salud de la población orientado a la verificación continua de la eficacia, seguridad y calidad de los productos y de mejorar la disponibilidad de medicamentos que cumplan con dichos caracteres, es que la ANMAT, a través de diversas disposiciones, ha reglado las situaciones específicas en las cuales deba emitirse la autorización efectiva de comercialización de un medicamento biológico, vacuna o radiofármaco y, en consecuencia, actualizar los requerimientos para cada una de ellas considerando sus particularidades.

Mediante la Disposición 6897/2000, la ANMAT establece que, previo a la comercialización de una especialidad medicinal inscripta en el Registro de Especialidades Medicinales (REM), debe conducirse una verificación técnica que permita corroborar la información de producción y control aportada para la obtención del registro sanitario.

Una vez inscripta la vacuna en el REM, la Disposición 9709/2019 establece que deberá solicitar la autorización efectiva de comercialización para iniciar su distribución y venta (artículo 1), no pudiendo quedar pendiente ningún trámite relativo al producto en cuestión (artículo 3). ${ }^{29}$

29 Disposición ANMAT 9709/2019. Disponible en: https://www.boletinoficial.gob.ar/detal- 
¿A cuales otros supuestos se aplica la referida autorización de comercialización de vacunas?: a) a las transferencias y cambios de titularidad de certificados de de la vacuna en el REM; b) cuando la vacuna inscripta en el REM no se haya comercializado o haya discontinuado su importación/elaboración previo a la vigencia de la reglamentación de inscripción en el REM específica para la vacuna; y c) cuando a la vacuna inicialmente autorizada a ser importada totalmente terminada se le autorice el cambio de sitio de elaboración o sitio de elaboración alternativo en la República Argentina (artículo 2).

La solicitud de autorización efectiva de comercialización deberá ser presentada dentro del año de obtenido el certificado de inscripción en el REM o de finalizada la transferencia o cambio de titularidad adjuntando toda la documentación completa requerida (artículo 16). La autorización se otorgará en el plazo de 45 días hábiles administrativos, luego de comprobado un resultado favorable en el trámite de verificación técnica ante la ANMAT, no pudiendo introducirse modificaciones -salvo las necesarias que requiera el ente- respecto a la información y documentación exigidas (artículos 4, 5 y 9). No puede efectivizarse la distribución y comercialización hasta que la ANMAT emita la respectiva disposición de autorización (artículo 11).

Igualmente, en el contexto actual de pandemia, el artículo 10 de la Disposición establece que la ANMAT puede expedirse antes de los 45 días "cuando por razones sanitarias fundadas, tales como situaciones de emergencia, resulte imperativa una autorización expeditiva”.

Si se denegara la solicitud de autorización de comercialización, el titular del certificado de inscripción ante el REM podrá presentar una nueva solicitud ante la ANMAT. De resultar nuevamente denegada, se cancelará el certificado de inscripción en el REM (artículo 13).

\section{La licencia obligatoria del artículo 45 de la Ley 24481}

Tratándose de un derecho de propiedad aquel que otorga la titularidad de la patente de la vacuna, quien lo detente puede usar y disponer de este, conforme surge del artículo 14 de la Constitución. En ese sentido, establece el artículo 8 de la Ley 24481 que el inventor o sus causahabientes tienen el derecho de cederlo o transferirlo (al derecho a la patente) por cualquier medio lícito y concertar "contratos de licencia".

Como dice Rozansky (1994), el contrato de licencia de patente "es el resul- 
tado de una negociación entre el titular del derecho y un tercero que, de mutuo y común acuerdo, entienden útil asociarse para explotar el invento" (p. 39), obligándose el tercero licenciatario a pagar un precio al propietario licenciante, denominado "regalía".

Las licencias obligatorias, por el contrario, se dan cuando "el Estado interviene y obliga al titular de la patente a otorgar compulsivamente a otro, generalmente un competidor, la autorización de explotación” (Rozansky, 1994, p. 39). De aquí surge la importancia práctica de reconocer al derecho de la propiedad intelectual como un derecho humano de propiedad, porque si lo entendemos de esta manera, la procedencia de las licencias obligatorias debe ser interpretada con criterio restrictivo, como mecanismos excepcionales a los derechos que la patente confiere, en un contexto de pandemia.

En este sentido, las licencias obligatorias operan como verdaderos límites al derecho de propiedad. Límites a la propiedad privada que ya venían reconocidos desde la Doctrina Social de la Iglesia, a través de los Principios Permanentes de dignidad de la persona humana, bien común, el destino universal de los bienes, de solidaridad, subsidiariedad y de participación; todos ellos apreciados en su unidad, conexión y articulación (Migliore, 2013, p. 39).

La armonía de intereses públicos y privados debe llevar a que la eficiencia buscada en la creación de nuevos medicamentos tenga en cuenta la necesidad externa al sistema de incentivos, puesto que la eficiencia no es un fin en sí mismo, sino que es la medida de qué tan bien estamos promoviendo los valores esenciales; aquella no tiene sentido sin valores o principios (Schötz, 2013d, p. 140).

Un modo de buscar esa eficiencia puede ser la licencia obligatoria, otorgada en condiciones de justicia. Incluso podríamos considerarla, ante casos de extrema necesidad, como parte del contenido esencial del derecho de propiedad al fijarle sus límites. Así, el interés público puede justificar límites a la propiedad. Igualmente, en este caso en particular, no se priva del derecho al titular, solo se disminuye el valor que podría obtener en caso de ejercer plenamente la exclusividad que confiere la titularidad de la patente (Schötz, 2013d, p. 140).

Las patentes no solo deben contribuir a una mejora en el acceso a los mercados, dice Schötz, sino también a una noción de bienestar social más amplia, incluyendo a la integridad personal, la dignidad humana, el acceso a la salud y a la información, entre otros objetivos (Schötz, 2013d, p. 157).

Concretamente, esto puede verse en el espíritu de la Declaración de la Cuarta Conferencia Ministerial de la Organización Mundial del Comercio, celebrada en la ciudad de Doha -o Declaración de Doha- (Organización Mundial del Comercio, 2001). Esta contiene mandatos para las negociaciones sobre una serie de 
cuestiones y relativos a la aplicación de los acuerdos concretados en el marco de la OMC. Específicamente, en su párrafo 17 resalta la importancia de interpretar y aplicar el Acuerdo sobre los ADPIC de manera tal que apoye la salud pública, promoviendo tanto el acceso a los medicamentos existentes como a la investigación y desarrollo de nuevos medicamentos.

Así, los Estados podrán establecer cuándo corresponde concederlas, bajo qué recaudos, en qué condiciones, plazo, etc. Lo que es claro es que se tratan de supuestos que se dan en condiciones de emergencia y excepcionales; serán luego los órganos administrativos o judiciales quienes deban llevar adelante la tarea de ponderación sobre estos instrumentos internacionales. Eventualmente, dice Iannello (2013b, p. 200), podrá hacerlo el órgano de solución de controversias de la OMC.

Si bien la Ley 111 no regulaba las licencias obligatorias, cierta doctrina sostenía su operatividad por la Ley 17011, que ratificó el Convenio de París que las regulaba en su artículo 5 (Chaloupka, 1987, p. 40). Actualmente, estas se encuentran reguladas en los artículos 42 a 50 de la Ley 24481, que toman como base el artículo 31 del Acuerdo ADPIC.

La regulación que hace el ADPIC sobre el licenciamiento obligatorio, en el caso particular de productos vinculados al cuidado de la salud, tiene sentido en cuanto la OMC ha dicho que sus acuerdos no son ajenos a las cuestiones sanitarias. Y, lo que es más, son una prioridad, pudiendo los Gobiernos, en caso de ser necesario, hacer caso omiso de los compromisos contraídos en el marco de la OMC para la protección de la vida y la salud humana que revisten de una importancia mayor (Organización Mundial del Comercio, 2002).

Hay ciertas condiciones para limitar el derecho del titular de la patente en interés de la salud y de la alimentación públicas. Primeramente, ser materia patentable y estar protegido por el ordenamiento patentario, por ende, siguiendo a Schötz y Rapela (2020, p. 8), cabe excluir de la aplicación de las licencias obligatorias los siguientes casos:

1) Si el producto o proceso aún no existe, es una completa abstracción aplicar una licencia obligatoria. Esto es porque el producto no ha sido desarrollado y, por lo tanto, no podrá cumplirse con los requisitos que exige el INPI para siquiera atravesar el filtro del examen preliminar de la solicitud de la patente.

2) Si no se solicitó la patente sobre un producto o proceso ya desarrollado, carece de sentido aplicar una licencia obligatoria sobre algo que no dispone de protección y es de libre disponibilidad. Máxime si todavía no ha sido divulgado y está protegido por la Ley de Confidencialidad o normas complementarias. Tampoco cuando la patente ha sido solicitada o concedida en el extranjero, pero 
no en el país: esa información estaría en el dominio público en el país donde se ejecuta la invención.

3) Si la patente concedida caducó por causas administrativas, renuncia del titular o expiración del período de protección, dado que no está protegido y es de libre disponibilidad.

4) Habiéndose solicitado, aún no ha sido concedido, o se encuentra en proceso de solicitud de un certificado de protección complementario, o un segundo uso de la patente original, o un título separado.

A los efectos de este trabajo, solamente me detendré a analizar la causal prevista en el artículo 45 referida a la licencia obligatoria en contexto de emergencia sanitaria o de seguridad nacional y su vinculación con la actual situación de pandemia ocasionada por el coronavirus.

En efecto, el artículo 45 de la Ley de Patentes establece en ese sentido que:

\begin{abstract}
ARTÍCULO 45. El Poder Ejecutivo Nacional podrá por motivos de emergencia sanitaria o seguridad nacional disponer la explotación de ciertas patentes mediante el otorgamiento del derecho de explotación conferido por una patente; su alcance y duración se limitará a los fines de la concesión.
\end{abstract}

Es un supuesto de aplicación del poder de policía amplio que posee el Estado ante situaciones particulares de emergencia. El poder de policía o de reglamentación es una función estatal en virtud de la cual opera la restricción de derechos de los particulares en favor del interés público, en virtud de la relatividad de derechos que surge de los artículos 14 y 28 de la Constitución. Ahora, al encontrarnos en una situación de emergencia (como puede ser una pandemia), el poder de policía adquiere una especial relevancia porque se vuelve más amplio, restringiendo aún más intensamente el ejercicio de los derechos individuales para beneficio del interés general transitoriamente. En palabras de Humberto Quiroga Lavié (2001): "La respuesta constitucional a la situación de emergencia es un ejercicio particular del poder de policía” (p. 747).

Este poder de policía "amplio" o "de emergencia" ya había sido admitido por la Corte Suprema de Justicia en el fallo Ercolano c/Lanteri de Renshaw (1922) y luego reiterada en los fallos Etchehon y González, expresando la Corte que hay circunstancias excepcionales que, por la dedicación de la propiedad privada a un intenso interés público y por las condiciones en las que esta se explota, justifican la intervención estatal en protección de los intereses vitales de la sociedad. ${ }^{30}$

30 Fallos: 136:161 y 193. 
Siempre que se emita una licencia obligatoria el Estado debe reconocer que es el único medio accesible para lograr el fin propuesto; que es por tiempo determinado hasta que cese la emergencia; que las garantías de aplicación de la licencia se enmarcan en un estado social y democrático de derecho reconociendo las reglas del debido proceso, incluyendo la necesidad de revisión jurisdiccional de las decisiones (Iannello, 2013b, p. 201).

Pero, a su vez, en el marco de la pandemia nos referimos a una emergencia sanitaria, es decir, una situación excepcional, de gravedad, inevitable, transitoria, en la que se pone especialmente en peligro el derecho a la salud de la población. Si bien estos derechos no están expresamente contenidos en el texto constitucional, surgen implícitamente en virtud del artículo 33 de la Constitución y están expresamente incorporados vía artículo 75, inciso 22 en los instrumentos internacionales de derechos humanos con jerarquía constitucional. Así, el artículo 12.1 del Pacto Internacional de los Derechos Económicos Sociales y Culturales (PIDESC) establece que el Estado reconoce el derecho de toda persona al disfrute del más alto nivel posible de salud física y mental, y, a su vez, establece como obligaciones a cargo del Estado: la reducción de la mortinatalidad y de la mortalidad infantil y el sano desarrollo de los nińos; el mejoramiento de todos los aspectos de la higiene del trabajo y del medio ambiente; la prevención y el tratamiento de las enfermedades epidémicas, endémicas, profesionales y de otra índole y la lucha contra ellas y la creación de condiciones que aseguren a todos asistencia médica y servicios médicos. Luego, otros instrumentos (jerarquizados o no) imponen otras obligaciones, como el Protocolo Facultativo de San Salvador y la Convención de los Derechos del Niño, en similares términos que el PIDESC.

Bajo ciertas circunstancias, los particulares también pueden estar obligados a proveer los medios para asegurar el derecho a la salud junto con el Estado. De modo general, la obligación de los particulares respecto a los derechos humanos se puede desprender del párrafo introductorio de la Declaración Universal de los Derechos Humanos (DUDH) (Schötz, 2013b, p. 112), al establecer que todos los pueblos y naciones deben esforzarse, a fin de que tanto los individuos como las instituciones promuevan los derechos y libertades reconocidos en ella.

Llegados a este punto, cabe preguntarse: ¿se puede encuadrar al COVID-19 en el artículo 45 de la Ley 24481 y posibilitar la concurrencia de una licencia obligatoria para los derechos de explotación de una eventual vacuna? ¿Estaríamos afectando en ese caso el derecho de propiedad que tiene el titular de la patente al alterar su ejercicio? ¿Se estarían afectando los artículos 14, 17 y 28 de la Constitución Nacional?

A la primer pregunta, la respuesta es sí, y la verosimilitud en el derecho nos la 
dan tanto el Decreto 260/2020, por el cual se prorroga por el plazo de un año la "emergencia sanitaria" declarada por la Ley 27541, como el Decreto 297/2020, dictado pocos días después, que establece el Aislamiento Social Preventivo y Obligatorio para combatir la pandemia declarada a principios de marzo por la OMS. Se dan los presupuestos objetivos en la situación actual para que proceda la aplicación del artículo 45 cuando se pretenda patentar la vacuna o algún tratamiento paliativo del coronavirus.

Con respecto a la segunda pregunta, también es un sí la respuesta, pero no se trata de una afectación inconstitucional en lo más mínimo. Tiene que ver con una noción de justicia distributiva, el bien común y el Estado en cumplimiento de sus obligaciones de afianzar la justicia y promover el bienestar general, actúa en función de aquella al mantener relaciones contractuales y patrimoniales con las empresas en la adquisición de fármacos. La justicia, en este caso, requerirá intervenir distribuyendo cosas comunes, como el acceso a los medicamentos, y protegiendo a los menos dotados para restablecer el equilibrio (Schötz, 2013a, p. 81).

$Y$ en cuanto a la tercera pregunta, la respuesta entiendo que es un no, tal como lo dije en el párrafo anterior. En una situación de normalidad claramente lo sería, porque la procedencia de una licencia obligatoria es de carácter excepcional y de interpretación restrictiva, pero ante una situación de emergencia, el poder de policía adquiere una intensidad mayor para dar cumplimiento a los fines superiores del Estado de promover el bienestar general de los habitantes de la nación, corriéndose el límite de la "no alterabilidad" del ejercicio de los derechos en su reglamentación legal que impone el artículo 28 de la Constitución a otro límite que es la "no derogabilidad".

En este aspecto, me gusta siempre citar al Dr. Rodolfo Luis Vigo (2014), en cuanto dice que "los derechos humanos se asimilan a principios, pero lo importante es que éstos son mandatos de optimización en tanto mandan la mejor conducta jurídica posible según las posibilidades fácticas y jurídicas implicadas" (p. 60). En el caso que nos compete, estaríamos ante la pandemia y los recursos técnicos y científicos para el desarrollo de fármacos limitados como posibilidad fáctica, y las normas legales vigentes en materia de emergencia sanitaria y el respeto por los derechos humanos como posibilidad jurídica, debiendo garantizar la vigencia tanto del derecho de propiedad del titular de la patente como el derecho a la salud de todos aquellos que pueden verse afectados por el virus.

Continuando con las normas referidas a la licencia obligatoria del artículo 45, se plantea la necesidad de ir previamente por el camino de obtener una licencia voluntaria con el titular de la patente y luego ultima ratio ir por la vía de la licencia obligatoria (Iannello, 2013b, p. 195). Esto no es así y así surge expresamente 
del artículo 31, inciso b del Acuerdo ADPIC, ratificado por Argentina, en cuanto establece que los Estados miembros pueden eximirse de la obligación de constatar que el potencial usuario haya intentado obtener la autorización del titular de los derechos en términos y condiciones comerciales razonables y esos intentos no hayan surtido efecto en un plazo prudencial, en caso de emergencia nacional o en otras circunstancias de extrema urgencia, o en los casos de uso público no comercial, notificando al titular de los derechos en cuanto sea razonablemente posible.

Esta última eximición de la compensación adecuada al titular tiene vinculación con el problema de la demora en la distribución de los fármacos que conlleva la patente en el medio de una crisis sanitaria, no pudiendo ser compensada monetariamente la salvaguarda del derecho a la salud y la vida de toda una población. La particularidad de los intereses superiores y públicos que están en juego hace necesaria una intervención diferente por parte de la administración.

La licencia obligatoria la otorgará la autoridad competente -el INPI (artículo 47, inciso a de la Ley de Patentes)-, considerándola en función de las circunstancias particulares de cada caso (inciso b). Tratándose, en este caso, de un uso público no comercial, se informa sin demoras al titular de la patente (inciso c). La autorización se extiende a las patentes relativas a los componentes y procesos de fabricación que permitan su explotación (inciso d), v.rg. la sustancia activa de la vacuna, y, por el otro lado, al recipiente en el que está contenida; son dos líneas de producción diferentes. Los usos serán de carácter no exclusivo (inciso e). No podrán cederse, salvo con aquella parte de la empresa o de su activo intangible que la integre (inciso f). Se le reconoce, además, al licenciante la posibilidad de percibir una remuneración razonable según las circunstancias propias de cada caso, habida cuenta del valor económico de la autorización (inciso h).

En el caso de la licencia del artículo 45, no rige la regla del artículo 47, inciso g de que debe utilizarse para "abastecer principalmente al mercado interno", por lo que una vacuna producida y patentada en Argentina sometida al procedimiento del artículo 45 podría perfectamente utilizarse para abastecer a toda Hispanoamérica.

Hay que tener en cuenta que la licencia obligatoria del artículo 45 se mantendrá rebuc sic estantibus (García Sellart, 2001, p. 173). Así lo expresa el artículo 47, inciso i de la Ley de Patentes cuando establece que el alcance de la licencia y su duración "se limitará a los fines para los que hayan sido autorizados y podrán retirarse si las circunstancias que dieron origen a esa autorización se han extinguido y no sea probable que vuelvan a surgir". En el caso bajo análisis, probablemente sea cuando la OMS deje de catalogar al COVID-19 como una pandemia o cuando ya no se detecten nuevos casos en el país. A estos fines, el INPI está facultado para 
examinar, previa petición fundada, si dichas circunstancias siguen existiendo. Continúa el inciso diciendo que "al dejarse sin efecto estos usos se deberán tener en cuenta los intereses legítimos de las personas que hubieran recibido dicha autorización".

Sin perjuicio de la amplitud que tiene el poder de policía en este aspecto y de la celeridad que se busca en el procedimiento administrativo en la obtención de la licencia (v.rg. vedándole el efecto suspensivo a la concesión de los recursos interpuestos contra los actos administrativos relacionados con el otorgamiento de la licencia), el control jurisdiccional está plenamente garantizado, ya que en todos los casos las decisiones relativas a los usos no autorizados por el titular de la patente estarán sujetos a revisión judicial, como asimismo lo relativo a la remuneración que corresponda cuando esta sea procedente (artículo 48).

No estamos aquí frente a ninguna violación del derecho humano a la propiedad, sino ante una armonización entre este y el bien común, reflejado en la patente de la invención que se trate en el caso concreto como solución a la emergencia sanitaria vigente.

\section{Conclusiones}

1) La pandemia del COVID-19 tiene un impacto innegable en los derechos de la propiedad intelectual, en particular en materia de patentes tanto en su aspecto sustancial como procedimental.

2) Si bien no existe un tratamiento o vacuna comprobados contra el coronavirus, actualmente hay un gran número de proyectos en marcha para satisfacer la necesidad "deseo largamente esperado" que se expresa en el sentimiento colectivo de que la pandemia finalice, lo que facilitará la prueba de la actividad inventiva como requisito de la vacuna cuando se quiera patentar.

3) La vacuna es materia patentable en virtud del actual régimen legal y está sujeta a los requisitos que esta debe cumplir contenidos en el artículo 4 de la Ley 24481, es decir, ser una invención novedosa, que entrañe actividad inventiva y tenga aplicación industrial.

4) El procedimiento para su comercialización y distribución ante la ANMAT tiene una regulación específica por las disposiciones del ente, lo que deriva de un interés mayor de la Administración Pública en un control riguroso en la producción y distribución de estos productos.

5) A raíz del ASPO, el INPI ha establecido innovadores procedimientos digitales para facilitar el acceso a la información del solicitante de la patente.

6) La obtención de la patente otorga a su titular un derecho de propiedad pro- 
tegido por la Constitución Nacional, con los alcances que da el artículo 8 de la Ley 24481.

7) La licencia obligatoria del artículo 45 es perfectamente aplicable a la eventual vacuna o vacunas que se patenten en el país y en forma alguna viola los preceptos establecidos en los artículos 14, 17 y 28 de la Constitución Nacional, teniendo en cuenta el poder de policía amplio o de emergencia.

8) La licencia obligatoria del artículo 45 tiene una regulación específica en la sección pertinente de la Ley de Patentes, la cual la distingue de las demás licencias obligatorias, por ejemplo, lo referido a la necesidad de una negociación previa para intentar obtener una licencia voluntaria.

\section{Bibliografía}

Balbín, C. F. (2018). Manual de Derecho Administrativo (4ª ed.). Ciudad Autónoma de Buenos Aires: La Ley.

Beier, F. K. (1986). La importancia del sistema de patentes para el progreso técnico, económico y social. Derechos Intelectuales, 1, 11-37.

Bensadon, M. y Sánchez Echagüe, I. (2008). Criterios de patentabilidad en el ámbito químico-farmacéutico: un análisis comparativo. Derechos Intelectuales, 14, 17-72.

Causse, J. R. (2017). Manual de derechos reales. Ciudad Autónoma de Buenos Aires: Astrea.

Chaloupka, P. (1987). ¿In dubio contra patentem? Derechos Intelectuales, 2, 34-73.

García Sellart, M. (2001). Licencias Obligatorias. Derechos Intelectuales, 9, 160-175.

Iannello, P. A. (2013a). Algunos fundamentos ético normativos sobre las patentes de invención en temas de medicinas esenciales. En Schötz, G. J. (Coord.), Patentes y Medicinas Esenciales. La armonización entre el derecho a la salud y la propiedad intelectual (1 ${ }^{\text {a }}$ ed., pp. 51-71). Buenos Aires: Heliasta.

Iannello, P. A. (2013b). Principios y Propiedad Intelectual. El balance de derechos en el caso de licencias compulsivas a la luz de los principios de Buena Fe y Proporcionalidad en el Derecho Internacional. En Schötz, G. J. (Coord.), Patentes y Medicinas Esenciales. La armonización entre el derecho a la salud y la propiedad intelectual (1a ed., pp. ). Buenos Aires: Heliasta.

Kolker, P. (1996). GATT-ADPIC y la industria farmacéutica. Derechos Intelectuales, 7, 15-29.

Laquis, M. A. (s.f.). Indispensable reconsideración de la ley 17.011 de adhesión al Convenio de Paris, $L L, 147-1147$.

Migliore, J. (2013). Propiedad intelectual y doctrina social de la Iglesia. En Schötz, G. J. (Coord.), Patentes y Medicinas Esenciales. La armonización entre el derecho a la salud y la propiedad intelectual (1 ${ }^{\text {a }}$ ed., pp. 23-49). Buenos Aires: Heliasta.

O'Farrell, E. (1988). Patentes y medicamentos. Derechos Intelectuales, 3, 36-49.

Organización Mundial del Comercio. (2001). Declaración relativa al acuerdo sobre los ADPIC y la salud pública. https://www.wto.org/spanish/thewto_s/minist_s/min01_s/mindecl_trips_s.htm.

Organización Mundial del Comercio. (2002). Los acuerdos de la OMC y la salud pública - un 
estudio conjunto de la OMS y la Secretaría de la OMC (Comunicado de prensa 310). http:// www.wto.org/spanish/news_s/pres02_s/pr310_s.htm.

Panadeiros, M. (1991). Patentamiento en la industria farmacéutica argentina. Derechos Intelectuales, 5, 54-62.

Quiroga Lavié, H. (2001). Derecho constitucional argentino (Tomo 2). Santa Fe: Rubinzal-Culzoni. Rozansky, F. (1994). Armonización para la innovación y el intercambio. Derechos Intelectuales, $6,38-45$.

Rozansky, F. (1996). Nueva legislación argentina de patentes de invención. Derechos Intelectuales, 7, 124-148.

Sánchez Echagüe, I. (2007). Protección de los datos de prueba para el registro de productos farmacéuticos. Derechos Intelectuales, 13, 170-195.

Schötz, G. J. (2013a). El derecho a la salud y el derecho de propiedad como parte del bien común de la comunidad internacional. En Schötz, G. J. (Coord.), Patentes y Medicinas Esenciales. La armonización entre el derecho a la salud y la propiedad intelectual ( $1^{\text {a }}$ ed., pp. 73-99). Buenos Aires: Heliasta.

Schötz, G. J. (2013b). El derecho a la salud. En Schötz, G. J. (Coord.), Patentes y Medicinas Esenciales. La armonización entre el derecho a la salud y la propiedad intelectual (1a ed., pp. 101-125). Buenos Aires: Heliasta.

Schötz, G. J. (2013c). El Derecho de Propiedad. En Schötz, G. J. (Coord.), Patentes y Medicinas Esenciales. La armonización entre el derecho a la salud y la propiedad intelectual (1a ed., pp. 127-150). Buenos Aires: Heliasta.

Schötz, G. J. (2013d). El conflicto de derechos. En Schötz, G. J. (Coord.), Patentes y Medicinas Esenciales. La armonización entre el derecho a la salud y la propiedad intelectual (1a ed., pp. 152-182). Buenos Aires: Heliasta.

Schötz, G. J. y Rapela, M. (2020). Covid-19, Derechos de Propiedad Intelectual y Licencias Obligatorias; Revista Jurídica La Ley, 2020-C. https://papers.ssrn.com/sol3/papers.cfm?abstract_id=3631032.

Silberston A. (1987). The economic importance of patents. Londres: Common Law Institute of Intellectual Property.

Vázquez, A. R. (1991). Patentes Farmacéuticas. Derecho argentino y comparado. Derechos Intelectuales, 5, 38-53.

Vigo, R. L. (2014). Conferencia inaugural. Primer Congreso Internacional de Filosofía del Derecho. Escuela Judicial del Estado de México, México, 6 al 10 de octubre de 2014, Interpretación (argumentación) jurídica en el estado de derecho constitucional. Santa Fe: Rubinzal-Culzoni.

Zuccherino, D. R. y Mitelman, C. O. (1994). Una sólida protección de los derechos de propiedad intelectual como herramienta de desarrollo económico. El caso particular de los productos farmacéuticos. Derechos Intelectuales, 6, 80-109.

Zuccherino, D. R. y Mitelman, C. O. (2008). Criterios de patentabilidad en el ámbito químico-farmacéutico. Un análisis comparativo. Derechos Intelectuales, 14, 80-109. 
